\title{
Allocation of referrals within a child and adolescent mental health service
}

\author{
Sophie Roberts and lan Partridge
}

\begin{abstract}
Long wailing lists are a common problem in child and adolescent mental health services. We describe how referrats to the service in York are considered and allocated by a multi-clisciplinary team. The criteria for allocation to different professionals and speciallist feams are described and data representing a snapshot of reterrals and response rate over a three-month period presented, showing that most referrals are seen within two months. We postulate that consideration of referrals in this way is an effective and efficient way of running a sorvice.
\end{abstract}

Waiting lists and waiting times in child and adolescent mental health services (CAMHSs) are a common cause of distress to children's families, referrers and professionals within the service. A method is required to streamline the allocation of referrals so as to maximise usage of resources. Where general practitioners (GPs) have access to mental health professionals of different disciplines in adult psychiatric services, they tend to refer different patient groups to each professional (O’Neill-Byrne \& Browning, 1996). It is uncertain whether these specific referrals are always appropriate. Previous studies of CAMHSs have shown that there is a poor level of understanding about child mental health services among GPs (Markantonakis \& Mathai, 1990; Thompson \& Place, 1995) and paediatricians (Oke \& Mayer, 1991).

The York service provides for a local population of 280000 . The community team available to deal with these referrals consists of 1.5 consultant psychiatrists, 1.5 specialist registrars in psychiatry, 1.5 senior house officers in psychiatry, 1.1 clinical psychologists, 3 community psychiatric nurses (CPNs), 0.75 occupational therapists and 0.7 social workers.

\section{Allocation process and criteria}

An allocations meeting is held weekly between the heads of each discipline, all referrals, other than emergencies, are allocated in this multi-disciplinary format which considers the following criteria.

\section{Disciplinary function}

The nature of a referral may require referral to a specific discipline; this process acts as an initial filter. Inter- and intra-disciplinary specialisms and areas of expertise and interest are acknowledged.

\section{Specialist team}

A number of specialist teams operate at tier three (National Health Service Health Advisory Service, 1995). Areas covered by these teams include eating disorders, bereavement, autism spectrum, attention deficit disorder, paediatric liaison, risk assessment and family therapy. Allocation can be direct or following initial assessment.

\section{Sector}

To facilitate close liaison with tier one workers a sectorised service has been implemented. Tier two allocation follows such sectorisation.

\section{Urgency}

An assessment is made by the allocations team of the urgency of the referral. Overdose referrals are rapidly processed and seen the same day, other emergency referrals are dealt with by a CPN or psychiatric services and these may not reach the allocations meeting.

\section{Individual workloads}

A consideration of individual workloads is made as this promotes team cohesion and enables support. At times holding operations are appropriate. It is recognised that the CPN service, with its commitment to rapid response in the young person's own locality, is one of the major factors which avoids waiting times.

\section{Re-referrals}

If a young person is re-referred there is consideration given to the benefits or otherwise of seeing the same professional again. An alternative or team perspective may be indicated. 


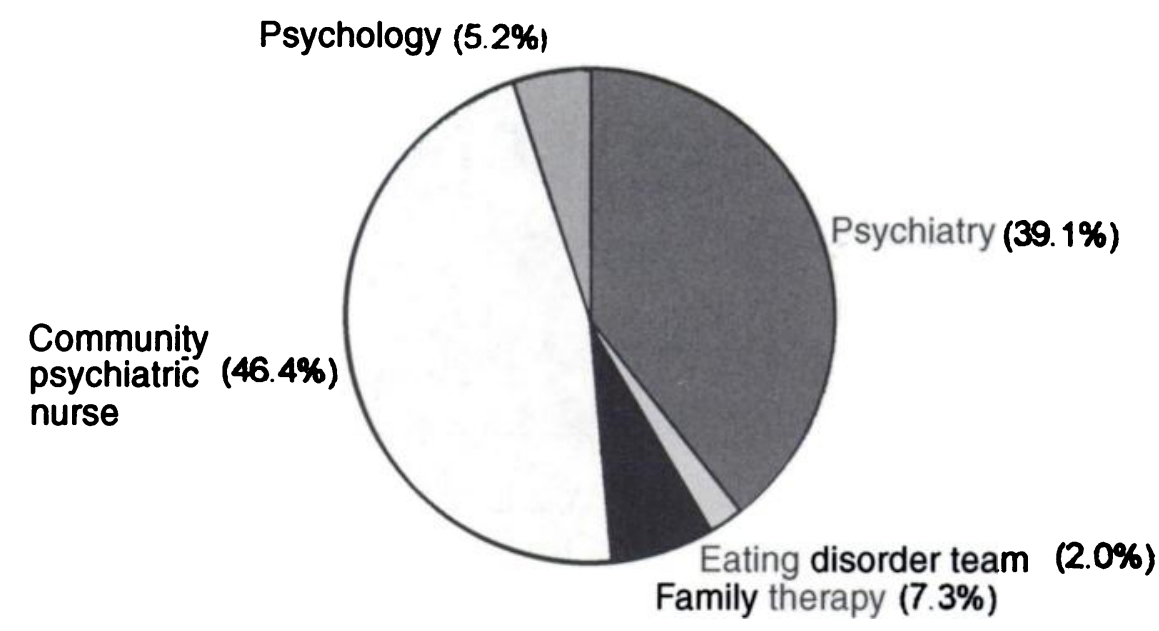

Fig. 1. Allocation between disciplines. (Psychology services were in transition with staff changes during this period. Other specialist teams' referrals are held within disciplines for recording purposes.)

\section{Training}

We are a training centre for all disciplines, and such training often includes tier two and tier three treatment programmes. It is recognised at the same time that trainees are not service providers, and therefore their case-loads are carefully monitored.

\section{Clarification}

Prior contact has often preceded referral and this is of considerable help to the allocations team. Not infrequently clarification is required and a nominated member of the allocations team will take responsibility for this liaison function, and obtain the necessary further information to facilitate appropriate allocation. It is recognised that where referrals arrive in a statutory context it is important as well as an efficient use of time to establish clear boundaries, communication networks and to identify and agree appropriate roles.

\section{Inter-agency work}

A number of other agencies may be involved in a particular case and ownership should always be clarified. There is always a danger when a number of professionals are involved in a case that confusion can exist as to where accountability and responsibility lie. Multi-disciplinary team consideration can minimise such dangers, an individual team member can coordinate the service involvement, if necessary organising a professionals' meeting wherein relevant issues can be addressed. Close liaison with other agencies on both a formal and informal basis can also lead to more appropriate referrals and increase awareness of service provision.

\section{Co-working}

Many referrals need an element of joint assessment and treatment which does not fit within the remit of a specialist team; such multi-disciplinary working can enable a fuller assessment as well as providing training, staff support, protection and supervision.

\section{Findings}

Reviewing this process of allocation with reference to a three-month period, the allocations detailed in Figure 1 were made, resulting in the response rates detailed in Table 1 .

Factors such as number of referrals and staff available are clearly going to influence the results but, as referrals and staffing are similar to many other CAMHS, we postulate that such a structured and multi-disciplinary allocations

Table 1. Response rates of different disciplines (\%)

\begin{tabular}{lllllll}
\hline Discipline/team & Immediate & 1-2 weeks & $3-4$ weeks & 5-8 weeks & 9-11 weeks & 12+ weeks \\
\hline Psychiatry & 16 & 11 & 24 & 38 & 6 & 5 \\
Psychology & 8 & & 8 & 16 & 28 & 40 \\
Community psychiatric nurse & 3 & 32 & 49 & 15 & 1 & 40 \\
Family therapy & & 50 & 50 & 50 & 5 & 40 \\
Eating disorder team & & 50 & & & &
\end{tabular}


process can contribute to reduction of waiting times.

\section{Comment}

Contractual obligations to purchasers, fundholding GP's block and individual contracts as well as pressure from referrers and from families are recognised as influences upon response rates and at times a degree of evaluation and management of such external anxieties is required.

The identified criteria represent an articulation and codification of the basic principles which guide the process of allocation. The response rate which follows illustrates that waiting lists can largely be avoided, with $85 \%$ of the total number of referrals being seen within two months. The value of the CPN service with a commitment to rapid response is particularly highlighted; this service which saw nearly half of the referrals was seeing $84 \%$ within four weeks.

We would contend that a process of allocation based upon multi-disciplinary consideration and flexibility allows for maximal use of resources wherein goals of appropriate allocation, efficient response rate and supportive team functioning can be facilitated. As pressures upon services increase, all three of these goals should be recognised.

\section{Acknowledgements}

We thank Paul Johnson, Greg Richardson and Barry Wright for their help in the preparation of this paper.

\section{References}

MARKANTONAKIS, A. \& MATHA. J. (1990) An evaluation of general practitioners' knowledge and satisfaction of a local child and family psychiatric service. Psychiatric Bulletin, 14, 328-329.

National Health Service Health advisory Service (1995) Together We Stand. London: HMSO.

OKE, S. \& MAYER, R. (1991) Referrals to child psychiatry - a survey of staff attitudes. Archives of Disease in Childhood. 66. 862-865.

O'NEILL-BYRNE. K. \& BROWNING. S. M. (1996) Which patients do GPs refer to which professional. Psychiatric Bulletin. 20. 584-587.

THOMPSON, A. \& PLACE, M. (1995) What influences general practitioners' use of child psychiatric services? Psychiatric Bulletin, 19, 10-12.

Sophie Roberts, Registrar in Psychiatry and "Ian Partridge, Social Worker, York Health, Lime Trees, Child and Adolescent and Family Unit, 31 Shipton Road, York YO3 6RE

*Correspondence

\title{
Use of the Care Programme Approach register by an inner- city old age psychiatry team
}

\author{
Jeremy Wallace and C. J. Ball
}

\begin{abstract}
The Care Programme Approach and its accompanying regitter were introduced in response to diliculties encounfered in a young cotult population. This paper describes the use of the register by an old age psychiatry service who do not routinely accept 'gractuate' patients. Few patients had a diagnosts of dementia and most had poychictic histories in excess of 10 years.
\end{abstract}

The Care Programme Approach (CPA) was introduced in 1993 in response to a number of highly publicised cases among the young adult popu- lation with severe mental illness. Concerns about the 'seamless' working of multiple agencies in the care of a given individual led to the formalising of the care through the use of a Care Programme Approach and its accompanying register (Kingdon, 1994). For old age psychiatrists interagency working has been at the core of their practice for many years. It is the nature of the patient group that they experience multiple problems, medical, psychological and social, which require input from a number of different 